\title{
Nos arredores da linguagem artaudiana: idéias que convergem na problemática da linguagem em Artaud
}

Vanessa Curty*

\author{
O homem é enfermo porque é mal construído. \\ Temos que nos decidir a desnudá-lo para raspar esse animálculo \\ que o corrói mortalmente, \\ deus \\ e juntamente com deus, \\ os seus órgãos (WILLER, 1986, p. 161).
}

O que nos arrepia no acima citado Para acabar de vez com o juízo de deus, de Antonin Artaud, não é tão somente a destituição do jugo do deus Pai, Filho e Espírito Santo; mas sim, pressentir o gérmen da implosão irreversível de um juízo que, até aquele momento, poderia assegurar a mediação entre todas as coisas.

Artaud não deixa de contemplar a crítica à ideologia cristã e aos métodos de fundação das religiões que se ligam a esta ideologia. Entretanto, longe de se limitar a uma série de heresias contra o cristianismo/instituição, agitam-se no interior das palavras de Artaud indagações muito mais pungentes.

São algumas dessas indagações que estão intrinsecamente ligadas à discussão da linguagem em Artaud. $O$ presente artigo destina-se justamente a verificar como vários pontos do pensamento artaudiano convergem na problemática da linguagem.

Em O teatro e seu duplo (1999) Artaud preconiza o teatro da crueldade; um teatro de uma crueldade que "[...] não exclui a violência e o sangue vertido, mas recorre a eles apenas ocasionalmente" (FELÍCIO, 1996, p. 79).

Movendo-se através dos textos de Artaud chega-se mesmo a um teatro que acordaria, de forma brutal, sensações há muito adormecidas; um evento que, exilado do conforto e da segurança com que o racionalismo do teatro psicológico impregnava a cena, dirigir-se-ia a "[...] nervos e coração" (ARTAUD, 1999, p. 95).

A crueldade artaudiana se apoiaria num ato de coragem, que, repelindo a tradução anêmica das experiências, dos conhecimentos eminentemente humanos, por uma lógica exterior à sensibilidade humana, abriria as "portas da percepção” à apreensão ultra-sensível do mundo. Em substituição à imaterialidade, à metafísica, do logos pela óptica sensualista do mundano, Artaud (1999, p. 134) "[...] disse crueldade como poderia ter dito 'vida' ”.

A idealização do teatro cruel planeja a fuga do que Jaccard definiria como o "deserto

\footnotetext{
* A autora é graduada em Artes Cênicas pela Universidade Estadual de Londrina (UEL), especialista em História e Teorias da Arte por esta mesma universidade, mestranda em teatro pela Universidade do Estado de Santa Catarina sob orientação do Prof. Dr. Edélcio Mostaço.
} 
supercivilizado que nunca pára de se estender" (JACCARD, 1989, p. 14). Ligado a uma concepção vitalista do mundo, que se lança à busca pela expressão selvagem, esse teatro (sem abolir o uso do intelecto; mas antes, para localizar o intelecto como mais um dos nossos sentidos, colocando-o em pé de igualdade com os demais) convidaria o homem a retornar ao mundo dos instintos, a sua condição primeira de animal. O regresso do homem, o desnudamento dos sentidos que lhe foram maculados, domesticados, pelo racionalismo cartesiano, implica o impulso ao retraimento do divino.

Em Artaud a derrocada de Deus representa o esboroamento da concepção platônica de um mundo das idéias que, sendo anterior ao mundo das aparências, ao mundo das coisas, corresponderia à verdade absoluta sobre tudo que existe.

É sobre esse mundo das idéias, surpreendido na filosofia platônica, que a linguagem se edifica. Ao menos a linguagem da fala e da escrita, que, obedecendo a uma ordem comunicativa, fixam campos de idéias a fim de mediar a "transmissão" do mundo das coisas entre as pessoas. $\mathrm{O}$ que para Artaud seria uma perversão. Esse seria o centro de todos os ataques que ele empreende contra o "deus-linguagem": para ele o mundo das coisas não pode ser apreendido pelas "miragens intelectuais" erigidas pela vontade comunicativa da linguagem, o mundo das sensações se mantém incomunicável.

Ao contestar a supremacia divina, o autor põe em xeque todo um discurso que entende o homem como imagem imperfeita e inacabada de um deus que tudo sabe e ao qual se deveria uma relação de semelhança. Artaud, a exemplo de Nietzsche - que anuncia a morte de Deus, mas não da divindade, propõe a insubordinação do humano a um deus maniqueísta que imputaria ao homem a sentença de persegui-lo na razão de todas as coisas.

Vale a citação:

Ele se dispôs de mim até o absurdo, este Deus; ele me manteve vivo em um vazio de negações encarniçadas de mim mesmo, ele destruiu em mim até os menores brotos da vida pensante, da vida sentida. Ele me reduziu a ser como um ser autômato que anda, mas um autômato que sentiria a ruptura da sua consciência (GUINSBURG; TELESI; MERCADO NETO, 1995, p. 250).

A morte de Deus se manifestaria então como a morte do "Duplo opressor que se apresentava sob a forma do logos" (FELÍCIO, 1996, p. 51). Importante faz-se neste momento abrir um parêntese para ressaltar a noção de duplo em Artaud, uma constante em sua obra.

A questão do duplo ultrapassa a identificação feita por Artaud entre teatro e todos os duplos que ele encontra para a arte teatral: vida, crueldade, peste, metafísica ${ }^{1}$.

O tema repercutirá na duplicação do deus acima descrito, nas instituições: Estado, Pátria, Família; todas elas instituições necrófilas que se alimentariam do homem-social, este ser que continuaria a financiar o pacto social, oferecendo sua própria vida como dízimo. Essas instituições seriam então os órgãos de Deus, os quais Artaud desejava extrair, os órgãos de 
um corpo social ao qual propõe o dilaceramento. Esse Deus também terá, como se esboçou há pouco, seu par na linguagem, manifestando-se na palavra enquanto simulacro do mundo físico, aquele que nomeia imperativamente o mundo das coisas de modo a banir o que foge à apreensão inteligível dessas coisas.

Voltando aos outros desdobramentos que se verificam a partir da morte de Deus, os quais irão cingir a questão da linguagem em Artaud: por detrás do aniquilamento de Deus reside ainda "[...] a morte do sujeito absoluto ao mesmo tempo que [se] designa o advento do 'sujeito cindido”" (FERRY, 1994, p. 52).

Através dessa constatação pressupõe-se que, se não se pode ter mais em Deus a certeza de uma verdade absoluta, o emanar infinito de todas as verdades incontestáveis, tudo será resumido a um conjunto de pontos de vista singularmente concebidos. Dentro dessa nova perspectiva, mesmo o ser humano, longe de ter assegurado o confluir de todas as suas idéias à construção de uma identidade una e indivisível, será levado ao dilaceramento, à fragmentação, do "eu". Dá-se assim a insurreição do "sujeito cindido".

Nas palavras de Artaud:

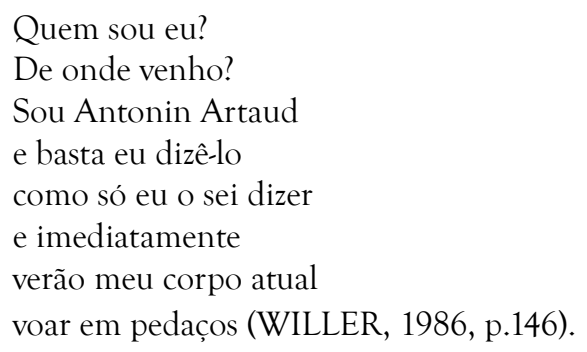

Conforme Eliana Robert Moraes, "fragmentar, decompor, dispersar: essas palavras se encontram na base de qualquer definição do 'espírito moderno"” (2002, p. 56). Artaud "[...] o mais didático e mais intransigente herói da auto-exacerbação na literatura moderna" (SONTAG, 1987, p. 17), é sem dúvida animado por esse espírito.

De acordo com Ruth Röhl, no seu O teatro de Heiner Müller (1997), a modernidade estética, distante da modernidade cultural (fundadora dos ideais modernos de progresso do conhecimento e crescimento social e moral), caracteriza-se por um projeto empreendido nos limites da batalha entre o representável e o concebível, o conceitual e o sensível, o mundo das idéias e o mundo das coisas. É justamente nesse terreno conflituoso, que Roland Jacard (1989) afirma já se delinear a partir do século XVII, que aflora a marca dessa modernidade: o individualismo ${ }^{2}$

Indo ao encontro do individualismo estabelecido pela modernidade, afirma Artaud (GUINSBURG; TELESI; MERCADO NETO, 1995, p. 207): "Lá onde outros propõem suas 
obras, eu não pretendo fazer outra coisa senão mostrar meu espírito”.

Esse sentimento individualista irá contaminar toda a concepção da escrita em Artaud. Ele não irá destinar seu texto à interlocução, no sentido de abrir possibilidade ao leitor de compartilhar, acompanhar a trajetória percorrida pelas idéias do escritor. $\mathrm{O}$ autor, imbuído no individualismo, procurará inventar "[...] uma leitura produtora do texto [...]" (FELÍCIO, 1996, p. 23), onde autor e leitor se encontram através do monólogo. Artaud quer, assim, nada mais que mostrar seu espírito, e o leitor... que reconheça o seu!

Sob o estigma do herói moderno nascem todos os autores que Virmaux (1990) congrega numa só "dinastia espiritual", a que Artaud pertence e da qual, vale lembrar, Nietzsche também faz parte.

$\mathrm{O}$ autor moderno, resistente ao conceito iluminista de literatura e à vinculação da arte a questões cognitivas e morais, inclina o embate do inteligível x sensível para a esfera da subjetividade, ligando, como é afirmado por Ferry (1994), a reprodução artística a uma estética da delicadeza ou do sentimento. Em vista disso o alicerce da literatura, e da arte moderna em geral, é a subjetividade. A produção artística sob esse signo se pauta, desse modo, pela alienação e não-obrigação à crítica social, e, enfim, pela ruptura com a voz coletiva da razão.

Não é à toa que os modernos abrem uma ferida que há muito o humanismo (movimento que elegeu, às avessas, o homem como centro do universo a partir da visão superobjetiva e imaterial da ciência e do pensamento crítico) tentava tapar: a loucura. Sintomas que, tipicamente, identificavam os ditos loucos, como a dissociação do "eu", a dificuldade de se expressar de forma objetiva, a potencialização dos conteúdos inconscientes e a internalização do mundo, passariam a sintetizar aquilo que seria o espírito da modernidade acima citado.

As descobertas da psicanálise contribuíram substancialmente para dissolver a idéia da indivisibilidade do eu. Além disso, o reconhecimento da personalidade enquanto entidade psíquica ficcionalmente elaborada, uma ilusão formada por um ego multifacetado, fez com que algumas correntes encarassem a loucura sob um novo âmbito. Porém Artaud, como observa Felício, apesar de não ter ignorado a psicanálise, não a considerava como ciência, por acreditar que se tratava antes de um método que "encerra toda organização verbal em preceitos ou fórmulas" (FELÍCIO, 1995, p. 20).

Vários dos experimentos lingüísticos de Artaud, contemporâneos e posteriores a sua internação em Rodez, são atribuídos à manifestação de um quadro psicótico. São eles glossolalias, palavras invertidas em arranjos a serem decifrados, mantras a serem lidos segundo ritmo depositado pelo leitor. Esses experimentos, entretanto, terão várias motivações além da loucura.

Antonin Artaud, que de 1937 a 1944 passou internado em vários sanatórios, seria louco ou apenas um herói romântico que levou às ultimas conseqüências o grito paroxísmico da modernidade? Talvez o próprio Artaud responda: “[...] um alienado é também um homem que a sociedade não quis ouvir e a quem ela quis impedir de dizer verdades insuportáveis" (GUINSBURG; TELESI; MERCADO NETO, 1995, p. 260).

Artaud, em seu ensaio: Van Gogh. O suicidado da sociedade (GUINSBURG; TELESI; MERCADO NETO, 1995, p. 257-273), constrói a idéia de que o estigma de louco surgiria da reação cívica da sociedade a uma atitude anti-social, delatora da "razão abstrata" (FELÍCIO, 
1996, p. 54); uma razão que, sustentada pelas relações de poder, usurparia a liberdade do homem, através da coerção física e moral, a fim de assegurar o continuísmo resignado da ordem vigente.

Segundo Felício (1996, p. 53), "Artaud exprime aquilo que Foucault busca ao escrever em A História da Loucura: mostrar que a loucura nasce da concepção de uma razão que tem necessidade de seu contrário para existir enquanto razão" (FELÍCIO, 1996, p. 53). A loucura passa a ser questionada como instituição historicamente construída.

A incapacidade de expressar em palavras as suas idéias, a refratariedade do ser como condição maligna limitadora das possibilidades humanas (e, por conseqüência, das possibilidades criativas): são estas as questões que, intrínsecas à morte do sujeito absoluto e ao advento da modernidade, pontuam toda a problemática da linguagem levantada por Artaud: "Meu pensamento foge-me de todas as maneiras possíveis, do simples fato do pensamento em si mesmo ao fato externo de sua materialização em palavras" (ARTAUD, 1970 apud ESSLIN, 1978, p. 25).

Antonin contemplava angustiado sua incapacidade de expressar em palavras o pulsar dos seus pensamentos; no tempo em que realizava a expressão a força vital do pensamento se esvaía. Indubitavelmente, ao assistir, imobilizado, à ação degenerante dessa incapacidade, Artaud era contra toda e qualquer forma de repetição. Acreditava que a palavra valia no momento anterior ao momento de seu nascimento, no exato e efêmero momento de fusão do significante e significado. Já no instante posterior, pertencente ao signo, a palavra de nada valia.

Opondo-se, assim, ao simulacro da palavra, à arbitrariedade legiferante do signo lingüístico, que sempre nasce pela repetição, Artaud execra a repetição como um todo. Isso porque "a repetição [para ele] separa de si própria a força, a presença, a vida. [...] Este poder de repetição dirigiu tudo que Artaud quis destruir e recebeu vários nomes: Deus, o Ser, a Dialética” (DERRIDA, 1971, p. 170).

Deus, para Antonin, é o absoluto que atenta contra a existência perecível do homem; aquele que, não podendo se manifestar de uma vez só, manifesta-se infinitamente: “[...] durante todas as vezes da eternidade como o infinito das vezes e da eternidade, o que cria a perpetuidade" (ARTAUD, 1945 apud DERRIDA, 1971, p. 170). O Ser é o invólucro no qual todas as "[...] forças de vida e de morte podem misturar-se e repetir-se na palavra" (DERRIDA, 1971, p. 170). Já a Dialética, é o terreno em que “[...] o verdadeiro é sempre o que se deixa repetir" (DERRIDA, 1971, p. 171).

O ser, para se fixar, precisa partir da afirmação de uma identidade. A consolidação da identidade se dá quando todos ou quase todos os atos do indivíduo (em todas ou quase todas as ocasiões da sua vida) reproduzem um mesmo discurso. A construção da identidade depende da constância de certos modelos de conduta, que, alinhavados entre si, devem ser condizentes com o discurso pelo qual o indivíduo responde. Assim, o ser é concebido através da repetição. Ao renegá-lo, Artaud renega aquele que não pode viver "[...] a não ser como possesso" (GUINSBURG; TELESI; MERCADO NETO, 1995, p. 262), aquele que, desde os seus mais ínfimos atos, afirma sua obediência a essa "lógica" que o mantém em estado de possessão. Faz-se necessário, então, que Antonin encontre outra forma de possuir a si 
mesmo, de possuir, como ele mesmo diz, "[...] todas as cintilações de meu [seu] eu por vir" (GUINSBURG; TELESI; MERCADO NETO, 1995, p. 209). O devir do seu ego, a busca de si, terão correspondência direta na procura que Artaud empreende através da linguagem; uma linguagem que, por não poder comportar um espírito incomensurável, deveria ser extrapolada.

Junto ao poder de repetição encerrado no ser, esse receptáculo que aprisiona e comprime todas as possibilidades do espírito, pulula outro tema: o suicídio. A apologia de Artaud ao suicídio não diz respeito à adesão à autoquíria como fuga desesperada da vida, mas, pelo contrário, é concernente a sua insubordinação à câmara mortuária do ser. $\mathrm{O}$ que Artaud sugere é "[...] um suicídio anterior, [...] um suicídio que nos fizesse dar a volta, porém para o outro lado da existência, não para o lado da morte (WILLER, 1986, p. 23). Ele em seguida esclarece: "[...] só este teria valor para mim. Não sinto apetite da morte, sinto apetite de não ser” (WILLER, 1986, p. 23). Artaud enxerga, então, no suicídio, um ato extremo de lucidez, contra a não-vida, contra a fixação do ser, rumo ao reconquistar de si mesmo: "se eu me mato, não será para me destruir, mas para me reconstruir, o suicídio não será para mim senão um meio de me reconquistar violentamente" (GUINSBURG; TELESI; MERCADO NETO, 1995, p. 247). O suicídio de um neurastênico, esse suicídio que caminha, às cegas, para a morte, não teria nenhum valor para o idealizador do teatro da crueldade; o suicídio que ele almeja é um ato planejado em direção à vida. Artaud confessa, em seu Van Gogh. O Suicidado da Sociedade, nunca ter tido obsessão pelo suicídio, isso, porque para se suicidar, ele sabia ter que "[...] esperar o retorno do meu [seu] eu" (GUINSBURG; TELESI; MERCADO NETO, 1995, p. 253), um eu que lhe permanecia inalcançável.

O desejo de Artaud por um suicídio anterior ao ser será o mesmo desejo que o impele ao encontro com a "[...] Palavra anterior às palavras" (ARTAUD, 1999, p. 63); a Palavra que não encerre a concretude do mundo numa estéril rede de significações.

Ainda a torturante inefabilidade do ser, a dificuldade de materializar a força do seu pensamento; as questões que, transportadas ou não para o âmbito da linguagem, estarão no cerne de todas as preocupações artaudianas. Tendo sido esclarecido o repúdio que Artaud dispensava ao ser, convém elucidar: o que é pensamento, para ele?

Artaud situa o pensamento no espírito, o que faz deste um pensamento sem bordas, sem limites. Antonin recusa um pensamento que, fechando o foco sob parte da imensidão do seu "eu" disperso, estabeleça um ponto fixo, a ser desenvolvido mediante uma cadeia dedutiva: "Eu não gosto da criação separada. Eu não concebo tampouco o espírito como separado de si próprio [...] me recuso a fazer diferenças entre qualquer dos minutos de mim mesmo" (GUINSBURG; TELESI; MERCADO NETO, 1995, p. 207).

Não fazendo diferenças entre qualquer dos minutos de si mesmo, Artaud desmantela as arestas do pensamento. Ele não quer um pensar que, se concentrando em apenas uma das questões trazidas pelo/no seu ser, através de uma operação mental, faça diferenças por entre ele mesmo. O pensamento deixaria de existir enquanto percurso de uma linha de raciocínio que ligaria a delimitação de um ponto no/do ser ao elemento final de uma fração, a qual retornaria desconexa ao seu ponto de origem. O pensamento transbordaria do campo conceitual para o sensível, transformando-se em ação: "ele não é mais teoria pura; aproxima 
ou distancia, fere ou acaricia [...] Recusa 'ser agido' a fim de se tornar uma cena visível que pede para ser revelada” (FELÍCIO, 1996, p.19).

A tentativa de alargar as amarras do ser e do pensamento não é específica ao projeto empreendido por Artaud. O gnosticismo, corrente mística de origem palestina, contemporânea a Cristo, já se lançava a essa empresa. Tendo em vista o grande número de autores que traçam paralelos entre as idéias artaudianas e a filosofia gnóstica (ESSLIN, 1978; SONTAG, 1986; VIRMAUX, 2000; WILLER, 1986; entre outros), e as alusões do próprio Artaud aos ensinamentos do gnosticismo (à Cabala, ao Zoar, ao Talmud e etc); caberia aqui rever alguns preceitos gnósticos, a fim de verificar se o gnosticismo caracteriza-se como uma das idéias-força que conduzem a problemática da linguagem em Artaud.

Sofrimento psicológico agudo, ansiedade metafísica, sensação de estar abandonado num mundo mau, a certeza de ser alvo de uma conspiração que conta com um número ilimitado de perseguidores; todos estes são temas gnósticos comuns à Artaud (que por hora não serão relacionados à esquizofrenia). Porém, no cuidado de economizar, ao menos momentaneamente, desnecessárias delongas sobre a matéria, Sontag contribui de modo significativo ao afirmar que "o problema da linguagem como Artaud o coloca a si próprio, é idêntico ao problema [gnóstico] da matéria” (SONTAG, 1986, p. 48). Quando a autora relaciona linguagem e matéria, em Artaud, ela orienta-se pela abjeção gnóstica ao corpo. Torna-se indispensável, então, discorrer sobre a visão do corpo no gnosticismo.

O corpo, para o gnosticismo, é essencialmente mau, é a casca inerte do ser onde as forças negras se manifestam. O corpo existe enquanto um grilhão que ata o ser a esse mundo anulatório dominado por demônios, por regras de convívio social. A presença do corpo é um despropósito que trama contra a abolição da existência dual - "corpo-mente, matériaespírito, bem-mal, luz-escuridão” (SONTAG, 1986, p. 45), contra a redenção a qual toda filosofia gnóstica se destinaria. Uma redenção que, operando pela mortificação do corpo, teria como fim último a destruição deste; à medida que ele deixaria de existir enquanto tal, frasco aprisionador do espírito, para ser transformado, transmutado, em presença carnal da imaterialidade. Só assim o corpo encontraria a acomodação perfeita da sua anatomia.

Artaud também aspiraria a outro corpo, por pensar este que se apresenta como recipiente castrador e mal-construído - "o homem é doente porque é mal construído [...]" (WILLER, 1986, p. 161). Em seu texto O teatro e a anatomia, o autor expõe bem sua idéia de um homem desalojado no seu próprio corpo: "o homem moderno supura e fede porque sua anatomia é má, e o sexo, em relação ao cérebro, está mal colocado na quadratura dos dois pés" (ARTAUD, 1946 apud VIRMAUX, 2000, p. 320). Artaud desejava uma transformação do corpo que não passasse pelas veredas da morte, mas que destruísse esse corpo conduzindoo em direção a sua original imortalidade (a que lhe foi tirada por Deus): "[...] o corpo humano é imortal. [...] só morre porque esqueceram de transformá-lo e de mudá-lo” (ARTAUD, 1948 apud VIRMAUX, 2000, p. 321).

A vontade gnóstica pela transmutação do corpo será reproduzida na relação que Artaud traça entre teatro e alquimia. $\mathrm{O}$ que Artaud queria através do seu teatro metafísico era, encontrar um teatro que pudesse "[...] resolver ou mesmo aniquilar todos os conflitos produzidos pelo antagonismo entre a matéria e o espírito, a idéia e a forma, o concreto e o 
abstrato, e fundir todas as aparências em uma expressão única que deveria ser semelhante ao ouro espiritualizado" (ARTAUD, 1999, p. 54).

Tendo Artaud o teatro como único instrumento de redenção, este deveria engendrar a transmutação alquímica da carne: a "[...] transformação orgânica e física verdadeira do corpo humano" (ARTAUD, 1948 apud VIRMAUX, 2000, p. 321); a transformação do corpo em um outro, um outro onde sensível e cognoscível não estivessem separados, um corpo sem contornos circundantes, sem divisórias apartadoras dos sentidos, um corpo total, um corpo sem órgãos.

O corpo sem órgãos torna-se, também, metáfora à linguagem que Artaud queria alcançar, uma linguagem que, unindo corpo e espírito, fosse: "[...] pensamento transformado em "matéria”" (SONTAG, 1986, p.48). Assim, “[...] aversão pelo corpo e [...] revulsão contra as palavras são duas formas do mesmo sentimento" (SONTAG, 1986, p. 48).

O corpo sem órgãos de Artaud não deixa de ser o corpo gnóstico. Ao buscar um corpo total, o filósofo almeja alcançar um sentir total. Os órgãos, dentro desse pensamento, definirse-iam como dezenas de vontades, estritamente, mundanas, ligadas a gozos materiais, que são comprazidos apenas pela carne. Preconizando um corpo sem órgãos ele se empenha na fusão de todos os sentidos, na criação de um único canal sensorial que permitisse dar vazão não só às sensações da carne, não só aos sentimentos do espírito, mas ao sentir do ser total; o ser que, transcendendo a dualidade corpo-mente, não precisaria de mais de um canal de percepção para existir. Obedecendo a essa mesma finalidade, ele chamará, enfim, a "[...] trituração de ossos, de membros e de sílabas [...]” (ARTAUD, 1948 apud VIRMAUX, 2000, p. 321). Porém, a questão se estende.

A idealização de um corpo sem órgãos levará Artaud ao tema da androginia - "[...] desejo de eliminar uma contradição, de juntar de vez o homem e a mulher, de combiná-los, fundilos numa coisa só [...]" (ARTAUD, 1934 apud WILLER, 1986, p. 36). O teatro da crueldade proclamará o seguinte imperativo: "Façam finalmente dançar a anatomia humana, de cima para baixo e de baixo para cima, de trás para frente e de frente para trás [...]” (ARTAUD, 1948 apud VIRMAUX, 2000, p. 329), nesse movimento, pelo que é avesso, não haveria espaço para uma sexualidade seccionada. O sexo e o ânus deveriam ser "decepados e liquidados" (ARTAUD, 1948 apud VIRMAUX, 2000, p. 330). O feminino e o masculino deveriam se fundir, como todos os outros contrários, num corpo que dança. E essa sua ânsia por um corpo que dança, que procede também da sua admiração pelo teatro oriental, passa a influir no embate que ele trava com a linguagem, fazendo-o voltar seu olhar para uma linguagemcorpo.

Tudo o que Artaud mais repudia na linguagem é a repetição e o fracionamento, a tentativa de reter o espírito em uma série de estados decompostos. Esses fantasmas assombraram-no sob diferentes formas. Manifestando-se à maneira da Hidra, monstro mitológico de várias cabeças, a repetição e o fracionamento tomaram face em Deus, no Ser, na Dialética... Em contrapartida, a quimera artaudiana de apreender, de uma só vez, a pluralidade da existência esteve presente em todos os momentos do teatrólogo, do poeta, do místico e do homem Artaud: em todos os duplos que encontrou para o teatro (vida, crueldade, peste, metafísica), no apelo cruel pela transmutação alquímica, no tema da androginia, na idealização do 
corpo sem órgãos, no desejo de um suicídio anterior, e também na biografia daquele que foi chamado por Virmaux (2000) de "homem-teatro"

São vários os veios que se abrem a partir da empresa, levantada por Artaud, de exterminar os condicionamentos impostos pela repetição e pelo fracionamento: individualismo (para não evocar o "rótulo" da modernidade), loucura, gnosticismo (filosofia mística oportuna, por possibilitar ao iniciado "rearranjar", "aplicar", a doutrina gnóstica de acordo com suas necessidades pessoais). Contudo, faz-se importante zelar para que nenhuma dessas fendas abertas pelo homem-teatro sejam postas, levianamente, em relação de causalidade com o mal que ele identificou em si e no mundo, com os questionamentos que ele promove; isso porque nada em Artaud é estanque, seu espírito, como ele mesmo afirmava, não poderia ser simplesmente assimilado por supostas relações de causa-efeito. Mas, e a questão da linguagem dentro do universo de Antonin? Seria a linguagem mais uma das faces do drama essencial que não cessava de atormentar Artaud? Ou é na linguagem que Artaud encontra a "materialização" do seu sofrimento (o sistema, irredutível, da representação), ao mesmo tempo que a chave "material" para resolvê-lo? Por ora, observando a ressalva ainda há pouco formulada, parece mais prudente continuar a considerar a discussão da linguagem, unicamente, como uma das mais importantes questões em Artaud. Porém, a partir desse estudo, poucas são as dúvidas de que, todos os ângulos desse personagem aqui analisados, sempre irão tocar a questão da linguagem.

\section{Notas}

\footnotetext{
${ }^{1}$ Não àquela idealizada pelo discurso lógico-racional, mas uma metafísica construída a partir de uma concepção ritualística do teatro: "O teatro é antes de tudo ritual e mágico" (GUINSBURG; TELESI; MERCADO NETO, 1995, p. 75).

${ }^{2}$ Importante se faz dizer que esse individualismo não remete à afirmação de uma identidade una; porém, não deixa de sublinhar a diferença como paráfrase do isolamento, da solidão e da incompreensão a que é fadado o homem moderno.

${ }^{3}$ Virmaux (2000) refere-se a Artaud como sendo o homem-teatro, na medida que este último fez da sua vida palco perfeito para a representação do seu drama essencial. Não conseguindo dar expressão aos seus pensamentos nos limites impostos pela arte teatral, levou o seu "teatro" a configurar sua própria existência.
}

\section{Bibliografia}

ARTAUD, Antonin. O teatro e seu duplo. Tradução de Teixeira Coelho. Revisão da tradução de Monica Stahael. 2. ed. São Paulo: Martins Fontes, 1999, p. 1-173.

DERRIDA, Jacques. A escritura e a diferença. São Paulo: Perspectiva, 1971, p. 107-177.

ESSLIN, Martin. Artaud. São Paulo: Cultrix, 1978, p. 11-109.

FELÍCIO, Vera Lúcia. A procura da lucidez em Artaud. São Paulo: Perspectiva, 1996, p. 1-196.

FERRY, Luc. Homo Aestheticus: a invenção do gosto na era democrática. São Paulo: Ensaio, 1994, p. 46-55.

GUINSBURG, J.; TELESI, Silvia Fernandes; MERCADO NETO, Antonio (Org.). Linguagem e vida: Antonin 
Artaud. São Paulo: Perspectiva, 1995, p. 11-290.

JACCARD, Roland et al. O indivíduo. Col. entrevistas do Le Mond. Trad. Sérgio Flaksman. São Paulo: Ática, 1989, p. 7-14.

MORAES, Eliane Robert. O corpo impossivel. São Paulo: Iluminuras/ Fapesp, 2002, p. 55-74.

RÖHL, Ruth. O teatro de Heiner Müller. São Paulo: Perspectiva, 1997, p. 5-189.

SONTAG, Susan. Sob o signo de saturno. São Paulo: L \& PM, 1986, p. 15-57.

VIRMAUX, Alain. Artaud e o teatro. 2. ed. São Paulo: Perspectiva, 1990, p. 1-377.

WILLER, Cláudio (Org.). Os escritos de Antonin Artaud. 2. ed. Porto Alegre: L\&PM, 1986 (Coleção Rebeldes e Malditos, 5), p. 7-167. 